\title{
Assessing smoking status in disadvantaged populations: is computer administered self report an accurate and acceptable measure?
}

\author{
Jamie Bryant ${ }^{1 * \dagger}$, Billie Bonevski $^{1 \dagger}$, Christine Paul ${ }^{2^{*+}}$ and Christophe Lecathelinais ${ }^{1 *+}$
}

\begin{abstract}
Background: Self report of smoking status is potentially unreliable in certain situations and in high-risk populations. This study aimed to determine the accuracy and acceptability of computer administered self-report of smoking status among a low socioeconomic (SES) population.

Methods: Clients attending a community service organisation for welfare support were invited to complete a cross-sectional touch screen computer health survey. Following survey completion, participants were invited to provide a breath sample to measure exposure to tobacco smoke in expired air. Sensitivity, specificity, positive predictive value and negative predictive value were calculated.
\end{abstract}

Results: Three hundred and eighty three participants completed the health survey, and 330 (86\%) provided a breath sample. Of participants included in the validation analysis, 59\% reported being a daily or occasional smoker. Sensitivity was $94.4 \%$ and specificity $92.8 \%$. The positive and negative predictive values were $94.9 \%$ and $92.0 \%$ respectively. The majority of participants reported that the touch screen survey was both enjoyable (79\%) and easy (88\%) to complete.

Conclusions: Computer administered self report is both acceptable and accurate as a method of assessing smoking status among low SES smokers in a community setting. Routine collection of health information using touch-screen computer has the potential to identify smokers and increase provision of support and referral in the community setting.

Keywords: Smoking, biochemical validation, carbon monoxide, touch screen computer, acceptability, accuracy

\section{Background}

Accurate assessment of smoking status is crucial not only for monitoring smoking prevalence, but also for assessing the effectiveness of smoking cessation interventions. Meta-analysis has shown that the accuracy of self-reported smoking status is high when assessed in the general population, particularly in community settings [1]. However self report tends to be compromised during smoking cessation

\footnotetext{
* Correspondence: Jamie.Bryant@newcastle.edu.au; Chris.Paul@newcastle.edu. au; Christophe.Lecathelinais@newcastle.edu.au

† Contributed equally

'Priority Research Centre for Health Behaviour, University of Newcastle, Hunter Medical Research Institute. Room 230A, Level 2, David Maddison Building, Callaghan NSW 2308 Australia

${ }^{2}$ Health Behaviour Research Group, Priority Research Centre for Health Behaviour, School of Medicine \& Public Health, University of Newcastle, Hunter Medical Research Institute. Room 268 Level 2, David Maddison Building, Callaghan NSW 2308 Australia

Full list of author information is available at the end of the article
}

trials where social desirability bias may influence self report, and among particular population groups where smoking is seen as undesirable, including among pregnant women [2-5], and among individuals with smoking related medical conditions including respiratory diseases $[6,7]$ and cancer [8]. It has therefore been recommended that smoking status be validated using a biochemical marker in certain circumstances including when assessing smoking status in special populations and in situations where contextual demand characteristics may influence accurate reporting [9].

As a result of a comprehensive population based approach to tobacco control, smoking rates in Australia have declined from $28.4 \%$ in 1989-1990 [10] to less than $17 \%$ in 2007 [11]. While Australia now has one of the lowest smoking rates in the developed world, rates remain significantly high among some disadvantaged 
sub-groups of the community [12]. For example compared to the whole population smoking prevalence rate of $16.9 \%$, smoking rates reported in the 2007 National Drug Strategy Household survey were 9\%-21\% higher among disadvantaged sub-groups, including individuals in the lowest socioeconomic quintile (the most disadvantaged; $25.9 \%$ ), the unemployed (38.2\%), and Aboriginal and Torres Strait Islanders (34.1\%) [11]. These estimates are however based on self report, the accuracy of which has not been established in highly disadvantaged or very low socio-economic status (SES) populations.

It is important to establish the accuracy of self-report as a measure of smoking status among very low SES populations for a number of reasons, including examining whether social desirability bias may be more or less evident among low SES groups than it is for the general population. Individuals receiving government welfare or community social support may perceive a level of disapproval from others if such support is spent on tobacco products, thereby increasing the likelihood of falsely reporting to be a non-smoker. Alternatively, the greater prevalence of smoking in low SES groups, as well as social norms conducive to smoking, may reduce such social desirability bias. In the absence of relevant data, it is difficult to know whether self-report data for disadvantaged populations provide overestimates or underestimates of the true prevalence of smoking in this population.

One method of assessing smoking status is using touch-screen computer technology. Touch-screen computers are an efficient and cost-effective way of collecting health information, often preferred over pen-andpaper methods [13]. Touch screen computers have been found to be acceptable in a wide range of settings and population groups, including among patients in cancer treatment and rheumatology clinics $[14,15]$, clients of community drug and alcohol treatment centres [16], and in general practice [17]. While the use of touch screen computers has been found to be acceptable among low income populations in primary care [18], no studies have explored the accuracy or acceptability of computer technology for assessing smoking status in a non-health community setting.

This study aimed to determine the accuracy (i.e. sensitivity, specificity, positive predictive value and negative predictive value) and acceptability of computer administered self report of smoking among socially disadvantaged individuals accessing a social and community service organisation (SCSO) for welfare support.

\section{Materials and methods \\ Design}

Data were collected as part of a larger cross-sectional health survey. Data collection occurred between February and October 2010.

\section{Setting \& Sample}

One SCSO in New South Wales, Australia, participated. Data was collected from three SCSO service sites located in Sydney (two services) and a regional area (one service). SCSOs are non-government, not-for-profit organisations that provide welfare services to highly disadvantaged individuals in the communities in which they are based. They provide a range of services to individuals including financial and family counselling, temporary accommodation, food and material aid, and child and family support $[19,20]$. Participants were adult clients attending the SCSO for emergency relief, which involved receiving financial or material assistance, including free grocery items, assistance paying bills, and assistance with purchasing medications.

\section{Recruitment \& Procedure}

Service attendees were invited by their caseworker at the end of their emergency relief interview to complete a touch screen computer administered health survey. Clients attending the services during the recruitment period who were aged over 18 years, able to speak or read English to a level that allowed completion of an English survey with or without assistance, and who were not distressed were eligible to participate. The gender and date of birth of nonconsenting clients were collected to assess participation bias. Clients who consented to participate were introduced to a research assistant who provided support to read and/ or complete the survey as necessary. Following completion of the touch screen computer health survey, participants were asked to complete a pen-and-paper survey to determine the acceptability of using the touch screen computer. Participants were then asked to provide a breath sample to measure breath carbon monoxide ( $\mathrm{BCO})$. $\mathrm{BCO}$ is a portable, low cost, immediate and non-invasive method of assessing smoking status [21], shown to have acceptable sensitivity and specificity [22]. Participants were unaware that they would be asked to provide this sample prior to completing the health survey.

\section{Measures}

Self-report

Survey items included questions about social demographics (e.g. gender, age, income, Aboriginal and Torres Strait islander status, employment and education), fruit and vegetable consumption, sun protection practices, smoking, physical activity, alcohol consumption and cancer screening behaviours (see Additional File 1). Only results relevant to the validation of smoking status will be reported here. All participants were asked "Do you currently smoke tobacco products?" (response options: 'Yes, daily', 'Yes, at least once a week', 'Yes, but less often than once per week' and 'No, not at all'). Time since last cigarette was determined by asking "When was the last 
time you smoked a cigarette, cigar or pipe?" (response options: 'Less than 4 hours ago', 'Between 4 and 8 hours ago', 'Between 8 and 12 hours ago and 'Longer than 12 hours ago'). In order to examine discrepancies between self reported smoking status and $\mathrm{BCO}$, exposure to passive smoke and heaviness of smoking (using the Heaviness of Smoking Index (HSI)) [23] were examined as explanatory factors. All participants were asked "In the last 24 hours have you been near other people who were smoking?" (response options: 'Yes' and 'No). To enable the calculation of the HSI, smokers were also asked "On an average day, how many cigarettes do you smoke?" and "How soon after waking up do you smoke? (response options: 'Within 5 minutes', '6-30 minutes', 31-60 minutes' and 'After 60 minutes).

\section{Touch screen computer}

All questions were presented on a touch screen computer using Digivey survey software [24]. The touch screen computer was a Dell Latitude XT2 (1.4 GHz processor).

\section{BCO}

Exhaled BCO measurements were obtained using a Bedfont Micro+ ${ }^{\text {TM }}$ Smokerlyzer ${ }^{\circledR}$ (Bedfont Scientific, UK, http://www.bedfont.com). Participants were asked to take a deep breath and hold for 15 seconds before exhaling slowly into the smokerlyzer. BCO monitors used in the study were calibrated by the manufacturer before the study commenced. A cut point of 6 parts per million (ppm) was used as recommended by the manufacturer to distinguish between smokers and non-smokers [25].

\section{Acceptability}

Acceptability of touch screen computer use was assessed using six questions answered on a five point Likert scale from 'Strongly agree' to 'Strongly disagree'. Items included "Completing the survey using the touch screen computer was enjoyable", "Completing the survey using the touch screen computer was easy", "Completing the survey using the touch screen computer was complicated", "Completing the survey using the touch screen computer was stressful", "I would be happy to complete a short survey about my health a few times a year when I came into [community service organisation]" and "I would prefer to answer this survey using a pen-and-paper survey".

\section{Power calculation}

Based on known smoking rates among groups that utilise social and community service organisations [19], it was assumed that approximately $50 \%$ of clients attending the service would be smokers. Based on this assumption, and a minimum required sensitivity and specificity of $80 \%$, a sample of 300 participants would allow estimation of sensitivity and specificity of selfreport versus $\mathrm{BCO}$ with $95 \%$ confidence intervals within $6.4 \%$ of the point estimate.

\section{Statistical Analysis}

Basic frequencies were calculated and Chi-square tests and Fisher's exact tests used as appropriate to explore differences between groups. Self-reported smoking status was compared to the established cut point (6 ppm) to determine the sensitivity, specificity, and positive and negative predictive values of self-report against $\mathrm{BCO}$, using $\mathrm{BCO}$ as the criterion measure. Due to the known short half life of $\mathrm{BCO}$, only individuals reporting daily or occasional smoking who indicated they had smoked a cigarette in the preceding 12 hours were included in the sensitivity and specificity analysis. The HSI was calculated by assigning a value of 0 for those reporting smoking between 0-10 cigarettes per day (CPD), 1 for those reporting 11-20 CPD, 2 for those reporting 21-30 CPD and 3 for those reporting 31 or more CPD. Responses to "How soon after waking up do you smoke?" were assigned values of 0 for those reporting $>60$ minutes, 1 for those reporting 31-60 minutes, 2 for those reporting 6 -30 minutes and 3 for those reporting $<5$ minutes. These two values were then summed to give a score with a range of 0 (low dependence) to 6 (high dependence).

\section{Ethics Approval}

This study was approved by the University of Newcastle Human Research Ethics Committee.

\section{Results}

Study Sample

A participant flow diagram is provided in Figure 1. A total of 727 clients attended the three sites during the study period of which 552 were approached to participate. The main reasons for not being approached to participate included having already completed the survey at an earlier visit (71 clients), being assessed by service staff as not suitable to participate (e.g. distressed, unwell, intoxicated or uncooperative, 39 clients), and not being able to speak or read English (13 clients). In total, 383 clients completed the touch screen survey (69\% consent rate), of which 330 clients (86\%) also provided a breath sample. Demographic details of the sample $(n=330)$ are presented in table one. Fifty-four percent of participants reported an income of less than AUD\$300 per week, 49\% were unemployed, 3\% reported primary school as their highest level of education and $65 \%$ reported secondary school as their highest level of education. Male participants were more likely than female participants to agree to participate (76\% vs. $67 \%$ respectively, $\left.\chi^{2}=5.5, \mathrm{p}=0.02\right)$, and participants recruited from the two inner-city services were more likely to agree to participate than participants from the regional service (80\% inner-city vs. $60 \%$ regional, $\chi^{2}=34, \mathrm{p}<0.001$ ). A total of 39 clients refused to provide a breath sample and a further 14 clients could not provide a breath sample due 


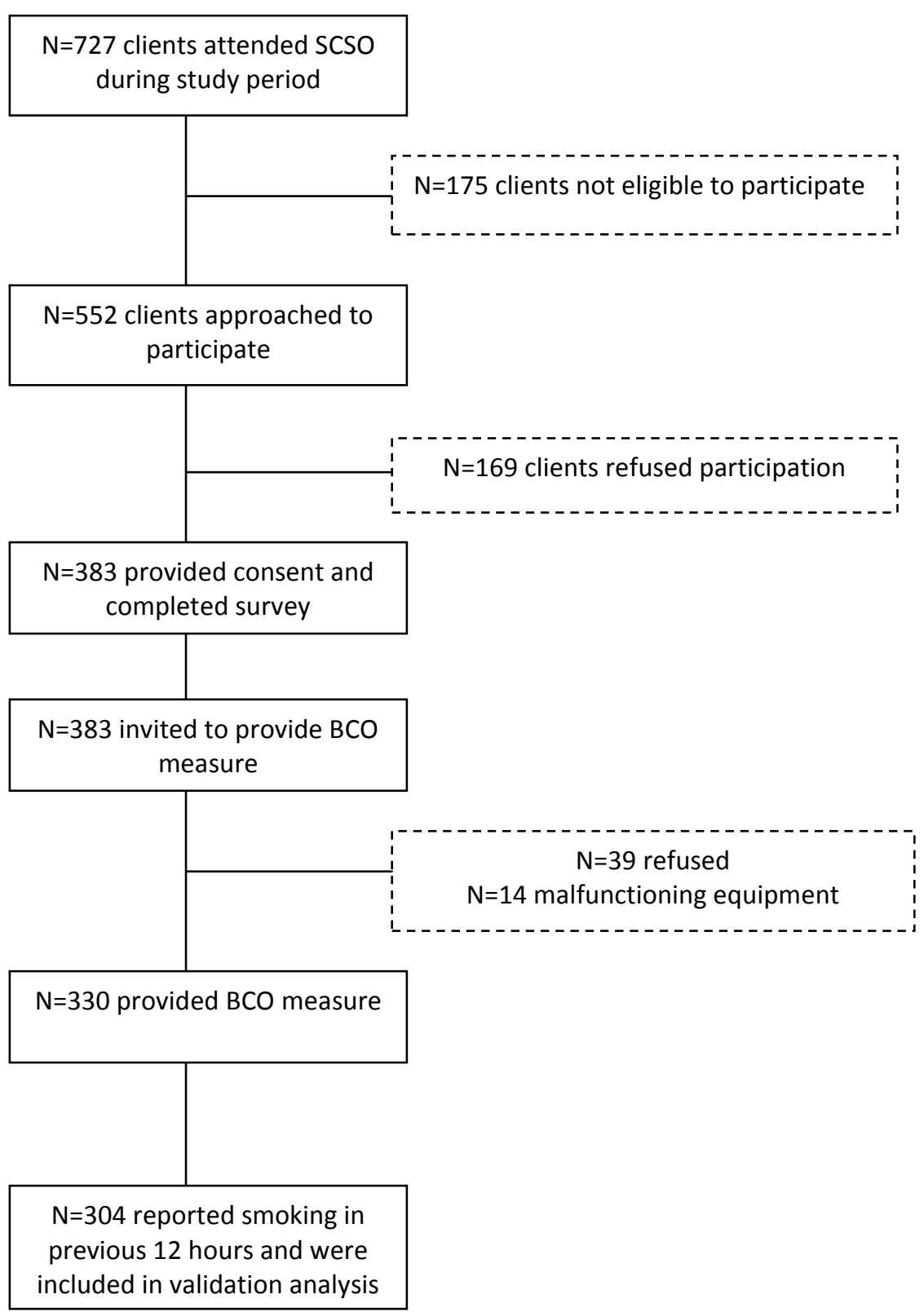

Figure 1 Participant flow diagram.

to malfunctioning equipment. There were no statistically significant differences in gender, age, Aboriginal or Torres Strait Islander status, marital status, education, income, employment characteristics or smoking status between those consenting and those not consenting to provide a breath sample (see table 1).

\section{Self-reported smoking status}

Of the clients included in the validation analysis $(\mathrm{n}=304)$, $59 \%(n=179)$ reported daily or occasional smoking (at least once per week or once per month). A total of $41 \%$ of clients $(n=125)$ reported being current non-smokers.

\section{Accuracy of self reported smoking status vs. BCO}

The smoking characteristics of participants included in validation analysis are reported in table 2 . Self reported daily or occasional smokers $(n=179)$ had a $B C O$ reading greater than or equal to $6 \mathrm{ppm}$ indicating a sensitivity of 94.4\% (CI 91.1\%-97.8\%). One hundred and sixteen self reported non-smokers had a $\mathrm{BCO}$ reading below $6 \mathrm{ppm}$ indicating a specificity of $92.8 \%$ (CI $88.3 \%-97.3 \%$ ). The positive predictive value was $94.9 \%$ and the negative predictive value was $92.0 \%$. Nine participants (3\% of the total sample) self reported being non-smokers but returned a $\mathrm{BCO}$ reading at or above the $6 \mathrm{ppm}$ cut point. 
Table 1 Demographic characteristics and smoking status of whole sample $(n=330)$ and participants not consenting to provide a breath tests $(n=39)$

\begin{tabular}{|c|c|c|c|c|c|}
\hline & \multicolumn{2}{|c|}{$\begin{array}{l}\text { Validation sample } \\
\qquad(n=330)\end{array}$} & \multicolumn{2}{|c|}{$\begin{array}{l}\text { Participants not consenting to breath test } \\
\qquad(\mathrm{n}=39)\end{array}$} & \multirow[t]{2}{*}{$\chi^{2}$} \\
\hline & $\mathrm{N}$ & $\%$ & $\mathrm{~N}$ & $\%$ & \\
\hline \multicolumn{6}{|l|}{ Gender } \\
\hline Male & 186 & 56 & 17 & 44 & $\left(\chi^{2}=1.79, p=0.18\right)$ \\
\hline Female & 144 & 44 & 22 & 56 & \\
\hline \multicolumn{6}{|l|}{ Age } \\
\hline$\leq 29$ years & 45 & 14 & 5 & 13 & $\left(\chi^{2}=1.64, \mathrm{df}=5, p=0.90\right)$ \\
\hline 30-39 years & 85 & 26 & 10 & 26 & \\
\hline $40-49$ years & 96 & 29 & 10 & 26 & \\
\hline $50-59$ years & 67 & 20 & 11 & 28 & \\
\hline $60-69$ years & 21 & 6 & 2 & 5 & \\
\hline $70+$ years & 16 & 5 & 1 & 3 & \\
\hline \multicolumn{6}{|c|}{ Aboriginal or Torres Strait Islander } \\
\hline Yes & 39 & 12 & 3 & 8 & $\left(\chi^{2}=0.51, p=0.47\right)$ \\
\hline No & 291 & 88 & 36 & 92 & \\
\hline \multicolumn{6}{|l|}{ Marital status } \\
\hline Never married/single & 178 & 54 & 22 & 56 & $\left(\chi^{2}=0.36, d f=4, p=0.46\right)$ \\
\hline Married & 24 & 7 & 5 & 13 & \\
\hline De facto/living with partner & 26 & 8 & 1 & 3 & \\
\hline Divorced/separated & 80 & 24 & 10 & 26 & \\
\hline Widowed & 22 & 7 & 1 & 3 & \\
\hline \multicolumn{6}{|l|}{ Highest level of education } \\
\hline Primary school & 10 & 3 & 1 & 3 & $\left(\chi^{2}=1.62, \mathrm{df}=4, p=0.8\right)$ \\
\hline High school years 7-10 & 157 & 48 & 15 & 38 & \\
\hline High school years 11-12 & 58 & 17 & 7 & 18 & \\
\hline TAFE & 56 & 17 & 8 & 21 & \\
\hline University Degree & 49 & 15 & 8 & 21 & \\
\hline \multicolumn{6}{|l|}{ Income } \\
\hline$<\$ 200$ & 53 & 16 & 5 & 13 & $\left(\chi^{2}=7.4, d f=5, p=0.19\right)$ \\
\hline$\$ 200-\$ 300$ & 124 & 38 & 10 & 26 & \\
\hline$\$ 300-\$ 400$ & 83 & 25 & 12 & 31 & \\
\hline$\$ 400-\$ 500$ & 31 & 9 & 2 & 5 & \\
\hline$<\$ 500$ & 19 & 6 & 6 & 15 & \\
\hline Prefer not to answer & 20 & 6 & 4 & 10 & \\
\hline Employment & & & & & $\left(\chi^{2}=6.8, d f=7, p=0.45\right)$ \\
\hline Full time & 4 & 1 & 0 & 0 & \\
\hline Part time/casual & 25 & 8 & 0 & 0 & \\
\hline Unemployed & 162 & 49 & 19 & 49 & \\
\hline Student & 15 & 5 & 3 & 8 & \\
\hline Unable to work & 15 & 5 & 7 & 18 & \\
\hline Home duties & 36 & 11 & 3 & 8 & \\
\hline Retired & 38 & 12 & 3 & 8 & \\
\hline Other & 35 & 11 & 4 & 10 & \\
\hline \multicolumn{6}{|l|}{ Smoking Status } \\
\hline Daily & 181 & 55 & 17 & 44 & $\left(\chi^{2}=1.9, \mathrm{df}=3, p=0.6\right)$ \\
\hline Occasional- weekly & 13 & 4 & 2 & 5 & \\
\hline Occasional- monthly & 11 & 3 & 2 & 5 & \\
\hline Non-smoker & 125 & 38 & 18 & 46 & \\
\hline
\end{tabular}

* Note: not all percentages add to $100 \%$ due to rounding. 
Table 2 Smoking characteristics of participants included in validation analysis $(n=304)$

\begin{tabular}{lcccc}
\hline & Male & Female & \multicolumn{2}{c}{ Total } \\
\hline & $\mathbf{n}$ & $\mathbf{n}$ & $\mathbf{n}$ & $\%$ \\
\hline Self reported smoking status & & & & \\
$\quad$ Smoker- daily or occasional & 108 & 71 & 179 & 59 \\
$\quad$ Non-smoker & 59 & 66 & 125 & 41 \\
Time since last cigarette* & & & & \\
$\quad$ < 4 hours & 99 & 66 & 165 & 92 \\
$\quad$ 4-8 hours & 8 & 5 & 13 & 7 \\
8-12 hours & 1 & 0 & 1 & 1 \\
Exposure to passive smoke in last 24 & & & & \\
hours & & & & \\
$\quad$ Exposure & 138 & 99 & 237 & 78 \\
$\quad$ No exposure & 28 & 38 & 66 & 22 \\
$\quad$ Missing & 1 & 0 & 1 & 0.3 \\
Heaviness of smoking index* & & & & \\
1-2 (Low dependence) & 39 & 26 & 65 & 36 \\
3-4 & 45 & 35 & 80 & 45 \\
5-6 (High dependence) & 24 & 10 & 34 & 19 \\
\hline
\end{tabular}

* Smokers only. $\mathrm{n}=179$. Note: not all percentages add to $100 \%$ due to rounding.

Ten self reported daily or occasional smokers (3.3\% of the total sample) returned a $\mathrm{BCO}$ below the $6 \mathrm{ppm}$ cut point. Heaviness of Smoking Index and exposure to passive smoke were analysed as explanatory variables for participants whose self reported smoking status and $\mathrm{BCO}$ measured smoking status were disparate. Analysis using Fisher's exact revealed no differences in misclassification according to HSI $(\mathrm{p}=0.12)$ or exposure to environmental smoke $(\mathrm{p}=0.57)$.

\section{Touch screen computer acceptability}

Acceptability of touch screen computer use is reported in table 3 . The majority of participants agreed or strongly agreed that completing the touch screen computer was easy $(88 \%)$ and enjoyable (79\%), and disagreed or strongly disagreed that completing the survey was stressful (92\%) or complicated (90\%). Most participants $(89 \%)$ agreed or strongly agreed that they would be happy to complete a survey about their health a few times per year. Only 19\% of participants agreed or strongly agreed they would prefer to complete the survey using a pen-and-paper survey.

\section{Discussion}

Because misreport often occurs when an individual fears disapproval regarding disclosure of smoking status [1], emphasis has been placed on confirming self report of smoking status using biochemical measures in high-risk population groups. Little work has examined the accuracy of self reported smoking among highly disadvantaged smokers who are often heavily nicotine dependent and live in communities with high smoking rates and pro-smoking social norms. This study aimed to assess the acceptability and accuracy of computer administered self-report of smoking among a low SES population attending a social and community welfare organisation.

Our findings indicate a strong agreement between self reported smoking status and $\mathrm{BCO}$ measured smoking status, with just over $6 \%$ of participants (an equal number of self reported smokers and non-smokers) misclassified by self report. This was significantly lower than levels of misreport found among other population groups, including pregnant Indigenous women [26]. No correlation was found between reports of being exposed to passive smoke or heaviness of smoking and misclassification, suggesting these smokers were misreporting their smoking status. These findings suggest that self-report is likely to be valid in determining smoking status in low SES community based populations.

The sensitivity and specificity for self-reported smoking against BCO at $94.4 \%$ sensitivity and $92.8 \%$ specificity are higher than mean figures derived in a review of validation studies using BCO in general community samples $(87 \%$ sensitivity, $89 \%$ specificity [1]. A sensitivity analysis conducted using Receiver Operating Curve analysis (results not reported) found that by lowering the cut-point to 5 ppm, sensitivity and specificity further improved (96.7\% and $91.2 \%$ respectively), and resulted in a greater percentage of participants being correctly classified (94.4\%) compared to our cut point of $6 \mathrm{ppm}$ (93.6\% correctly classified). Other published research has found that cutpoints lower than those recommended are optimal for

Table 3 Acceptability (\%) of touch screen computer use ( $N=330$ )

\begin{tabular}{|c|c|c|c|c|c|}
\hline & $\begin{array}{l}\text { Strongly } \\
\text { agree }\end{array}$ & Agree & $\begin{array}{l}\text { Neither agree or } \\
\text { disagree }\end{array}$ & Disagree & $\begin{array}{l}\text { Strongly } \\
\text { disagree }\end{array}$ \\
\hline Completing the survey using the touch screen computer was enjoyable & 17 & 62 & 17 & 4 & 0 \\
\hline Completing the survey using the touch screen computer was easy & 25 & 63 & 10 & 2 & 0 \\
\hline Completing the survey using the touch screen computer was complicated & 0 & 4 & 5 & 67 & 23 \\
\hline Completing the survey using the touch screen computer was stressful & 0 & 3 & 5 & 62 & 30 \\
\hline $\begin{array}{l}\text { I would be happy to complete a short survey about my health a few times a } \\
\text { year when I came into [service] }\end{array}$ & 22 & 67 & 9 & 2 & 0 \\
\hline I would prefer to answer this survey using a pen-and-paper survey & 5 & 13 & 24 & 40 & 17 \\
\hline
\end{tabular}

$\wedge$ Note: not all rows sum to $100 \%$ due to rounding 
certain sub-groups [27-29]. Future clinical research using $\mathrm{BCO}$ for monitoring or feedback should further explore optimal cut points, as well as determine the accuracy of self report among low SES individuals in high-demand situations, such as during smoking cessation trials.

The high level of acceptability of touch screen computer use in this population supports research demonstrating the utility of touch screen technology as an efficient method of routinely collecting information in health care settings $[16,17,30]$. Participants rated the touch screen computer as easy to use and enjoyable, and agreed they would be happy to complete a similar survey a few times each year. Given the high degree of acceptability, the potential for integrating the routine collection of health risk information into SCSOs should be further explored. These organisations are well placed to provide advice and referral regarding health care needs to the large number of socially disadvantaged clients seen for welfare and social support. Collection of health care information via touch screen computer may provide an efficient way of identifying those smokers and providing assistance with social and health care needs simultaneously.

The high consent rate for BCO testing (86\%) also indicates very good acceptability of BCO among clients attending the SCSO. It was the experience of the authors that the immediate return of results to clients often started conversations about smoking and quitting, suggesting a potential role for $\mathrm{BCO}$ as a clinical tool to educate and motivate low SES smokers who are not motivated to quit. While there is currently no strong evidence that biofeedback increases cessation attempts [31], BCO may be an acceptable and non-threatening way to engage hard-toreach groups with smoking cessation and prompt advice and referral, especially given the high prevalence of smoking identified in this setting.

\section{Limitations and Generalisability}

As participants were not told that their smoking status would be verified prior to self report of smoking status, these results may not be generalisable to situations where individuals are aware that the accuracy of their report will be confirmed. The limitations of $\mathrm{BCO}$ as a biochemical confirmer of smoking status should also be recognised. Because $\mathrm{BCO}$ is a short-term measure of exposure to tobacco smoke, with a half life of 2-8 hours [9], it is possible that self-reported smokers who had consumed their last cigarette longer than within 2-8 hours of providing a breath sample may have been incorrectly classified by BCO as non-smokers. To control for the short half life, we included in the sensitivity analysis only the smokers who reported smoking their last cigarette within the preceding 12 hours. Further, compared with other biochemical measures of confirming smoking status such as cotinine, BCO may not detect very low levels of smoking and can be influenced by environmental sources of CO [9]. However these limitations are outweighed by the practical advantages of using $\mathrm{BCO}$ which is an immediate, low-cost and portable measure of confirmation.

\section{Conclusions}

Computer administered self report is an accurate and acceptable method of assessing smoking status in a low SES sample of smokers in a community setting, with a low rate of misclassification identified. Routine collection of health information via touch screen computer holds potential as a way to improve the health of low SES individuals attending community welfare organisations.

\section{Additional material}

Additional file 1: Survey Items. Survey items completed by

participants.

\section{Acknowledgements and funding}

This research was funded by Cancer Council New South Wales as well as an Australian Postgraduate Scholarship and Cancer Institute New South Wales Research Scholar Award to JB. This research was supported by the University of Newcastle and Cancer Council New South Wales' Centre for Health Research and Psycho-oncology (CHeRP) with infrastructure support from the Hunter Medical Research Institute. The authors would like to thank the participating community organisations and their clients for taking part in this research. We would also like to acknowledge the support of Cancer Council NSW's Tackling Tobacco Program and would like to thank David Ip, Elizabeth Cridland, Angela Patterson, Brianna Pike and Sally Mitchell for their assistance with data collection.

\section{Author details}

${ }^{1}$ Priority Research Centre for Health Behaviour, University of Newcastle, Hunter Medical Research Institute. Room 230A, Level 2, David Maddison Building, Callaghan NSW 2308 Australia. ${ }^{2}$ Health Behaviour Research Group, Priority Research Centre for Health Behaviour, School of Medicine \& Public Health, University of Newcastle, Hunter Medical Research Institute. Room 268 Level 2, David Maddison Building, Callaghan NSW 2308 Australia.

\section{Authors' contributions}

$\mathrm{JB}, \mathrm{BB}$, and $\mathrm{CP}$ conceived of the study and were involved in its design and co-ordination. JB and BB supervised data collection. Statistical analysis was carried out by JB and CL. JB led manuscript preparation. All authors were involved in data interpretation and revised the manuscript critically for intellectual content. All authors approve of the final version of the manuscript.

\section{Competing interests}

The authors declare that they have no competing interests.

Received: 20 June 2011 Accepted: 21 November 2011

Published: 21 November 2011

\section{References}

1. Patrick DL, Cheadle A, Thompson DC, Diehr P, Koepsell T, Kinne S: The validity of self-reported smoking: A review and meta-analysis. Am J Public Health 1994, 84(7):1086-1093.

2. Owen L, McNeill A: Saliva cotinine as indicator of cigarette smoking in pregnant women. Addiction 2001, 96(1001-1006).

3. Russell T, Crawford M, Woodby L: Measurements for active cigarette smoke exposure in prevalence and cessation studies: why simply asking 
pregnant women isn't enough. Nicotine and Tobacco Research 2004, 6(Supplement 1):S141-S151.

4. Webb DA, Boyd NR, Messina D, Windsor RA: The discrepancy between self-reported smoking status and urine continine levels among women enrolled in prenatal care at four publicly funded clinical sites. J Public Health Manag Pract 2003, 9:322-325.

5. Walsh R, Redman S, Adamson L: The accuracy of self-report of smoking status in pregnant women. Addict Behav 1996, 21(5):675-679.

6. Lewis SJ, Cherry NM, McNiven R, Barber PV, Wilde K, Povey AC: Cotinine levels and self-reported smoking status in patients attending a bronchoscopy clinic. Biomarkers 2003, 8(218-228).

7. Monninkhof E, van der Valk $P$, van der Palen J, Mulder $H$, Pieterse M, van Herwaarden C, Zielhuis G: The effect of a minimal contact smoking cessation programme in out-patients with chronic obstructive pulmonary disease: a pre-post-test study. Patient Educ Couns 2004, 52:231-236.

8. Martinez ME, Reid M, Jiang R, Einspahr J, Alberts DS: Accuracy of self reported smoking status among participants in a chemoprevention trial. Prev Med 2004, 38:492-497.

9. SRNT subcommittee on biochemical verification: Biochemical verification of tobacco use and cessation. Nicotine and Tobacco Research 2002, 4:148-159.

10. Australian Bureau of Statistics: National Health Survey Lifestyle and Health. Catalogue No. 4366.0. Canberra; 1989

11. Australian Institute of Health and Welfare: 2007 National Drug Strategy Household Survey: detailed findings. Drug statistics series no. 22. Cat no. PHE 107. Canberra: AlHW; 2008.

12. Australian Institute of Health and Welfare: Australia's health 2010. Australia's health service no. 12. Cat. no. AUS122. Canberra: AlHW; 2010

13. Bonevski B, Sanson-Fisher R, Campbell E, Ireland MC: Do general practice patients find computer health risk surveys acceptable? A comparison with pen-and-paper method. Health Promotion Journal of Australia 1997, 7:100-106.

14. Newell S, Sanson-Fisher R, Girgis A, Stewart J: Are touchscreen computer surveys acceptable to medical oncology patients? Journal of Psychosocial Oncology 1997, 15(2):37-46.

15. Greenwood MC, Hakim AJ, Carson E, Doyle DV: Touch-screen computer systems in the rheumatology clinic offer a reliable and user-friendly means of collecting quality of life and outcome data from patients with rheumatoid arthritis. Rheumatology (Oxford) 2006, 45:66-71.

16. Shakeshaft AP, Bowman JA, Sanson-Fisher R: Computers in communitybased drug and alcohol clinical settings: are they acceptable to respondents? Drug Alcohol Depend 1998, 50(2):177-180.

17. Bonevski B, Campbell E, Sanson-Fisher R: The validity and reliability of an interactive computer and alcohol use survey in general practice. Addict Behav 2010, 35:492-498.

18. Bock B, Niaura R, Fontes A, Bock F: Acceptability of computer assessments among ethnically diverse, low-income smokers. Am J Health Promot 1999, 13(5):299-304.

19. Australian Council of Social Service: Australian community sector surveyReport 2010 Volume 1- National. 2010.

20. Bryant J, Bonevski B, Paul C, O'Brien J, Oakes W: Delivering smoking cessation support to disadvantaged groups: A qualitative study of the potential of community welfare organisations. Health Educ Res 2010, 25(6):979-990.

21. Wald NJ, Idle M, Boreham J, Bailey A: Carbon monoxide in breath in relation to smoking and carboxyhaemoglobin levels. Thorax 1981, 36:366-369.

22. Jarvis MJ, Tunstall-Pedoe H, Feyeraband C, Vesey C, Saloojee Y: Comparison of tests used to distinguish smokers from nonsmokers. Am J Public Health 1987, 77:1435-1438.

23. Heatherton TF, Kozlowski LT, Frecker RC, Rickert W, Robinson J: Measuring the heaviness of smoking: Using self-reported time to the first cigarette of the day and number of cigarettes smokerd per day. Br J Addict 1989, 84(7):791-799.

24. Creoso Corporation: Digivey Survey Suite. Arizona, USA; 3.1.36.0.

25. Bedfont Scientific: Micro+ Smokerlyzer. Operating Manual. Kent, England 2011.

26. Gilligan C, Sanson-Fisher R, Eades S, Wenitong M, Panaretto K, D'Este C: Assessing the accuracy of self-reported smoking status and impact of passive smoke exposure among pregnant Aboriginal and Torres Strait
Islander women using cotinine biochemical verification. Drug and Alcohol Review 2010, 29(1):35-40.

27. MacLaren DJ, Conigrave KM, Roberston JA, Ivers RG, Eades S, Clough AR: Using breath carbon monoxide to validate self reported tobacco smoking in remote Australian Indigenous communities. Population Health Metrics 2010, 8(2).

28. Cropsey KL, Eldridge GD, Weaver MF, Villalobos GC, Stitzer ML: Expired carbon monoxide levels in self-reported smokers and nonsmokers in prison. Nicotine and Tobacco Research 2006, 8(5):653-659.

29. Javors MA, Hatch JP, Lamb RJ: Cut-off levels for breath carbon monoxide as a marker for cigarette smoking. Addict Biol 2005, 100:159-167.

30. Wolfenden L, Dalton A, Bowman J, Knight J, Burrows S, Wiggers J: Computerized assessment of surgical patients for tobacco use: accuracy and acceptability. Journal of Public Health 2007, 29(2):183-185.

31. Bize R, Burnand B, Mueller $Y$, Rege Walther M, Cornuz J: Biomedical risk assessment as an aid for smoking cessation. Cochrane Database of Systematic Reviews 2009, (2. Art. No.: CD004705).

\section{Pre-publication history}

The pre-publication history for this paper can be accessed here: http://www.biomedcentral.com/1471-2288/11/153/prepub

doi:10.1186/1471-2288-11-153

Cite this article as: Bryant et al:: Assessing smoking status in disadvantaged populations: is computer administered self report an accurate and acceptable measure? BMC Medical Research Methodology 2011 11:153.

\section{Submit your next manuscript to BioMed Central and take full advantage of:}

- Convenient online submission

- Thorough peer review

- No space constraints or color figure charges

- Immediate publication on acceptance

- Inclusion in PubMed, CAS, Scopus and Google Scholar

- Research which is freely available for redistribution

Submit your manuscript at www.biomedcentral.com/submit
Ciomed Central 